\title{
March 2014 Critical Care Case of the Month: Interstitial Lung Disease
}

\author{
Seongseok Yun, MD PhD \\ Konstantin Mazursky, DO \\ Kahroba Jahan, MD \\ Enas Al Zaghal, MD \\ Department of Medicine \\ University of Arizona \\ Tucson, AZ 85724
}

\section{History of Present IIIness}

An 80 year-old man with a history of chronic obstructive pulmonary disease, asbestosis and interstitial lung disease, presented to the outpatient clinic with cough, sinus congestion and mild sputum. He was sent home with amoxicillin for the treatment of a sinus infection. However, he came back to emergency department with worsening respiratory symptoms including shortness of breath and persistent cough. He required 8-10 L/min of oxygen to maintain an oxygen saturation above $90 \%$.

PMH

- COPD

- Asbestosis

- Interstitial lung disease

- Diabetes mellitus, type II

- Hypertension

- Aortic valve replacement

\section{Medications}

- Fluticasone-salmeterol $250-50$ mcg inhaler

- Mometasone $50 \mathrm{mcg} /$ actuation nasal spray

- Furosemide $40 \mathrm{mg}$ PO daily

- Felodipine 5 mg PO BID

- Warfarin $3 \mathrm{mg}$ PO daily

- Insulin aspart 5 units SC injection before meals

- Insulin glargine 15 units SC injection night time

\section{Social History}

- 50 pack-year prior smoking history

- No ethanol or recreational drugs

- No recent travel history

- Significant history of asbestos exposure. 


\section{Physical Examination}

Vital signs: temperature $37.2{ }^{\circ} \mathrm{C}$, pulse 116 beats/min, respiratory rate $32-34$ breaths/min, blood pressure $179 / 77 \mathrm{mmHg}, \mathrm{SpO} 290 \%$ on $10 \mathrm{~L} / \mathrm{min}$ nonrebreathing mask (NRB).

General: Alert and oriented but appearing distressed, tachypneic and dyspneic Skin: Diaphoretic, no rash or lesions noted.

HEENT: Unremarkable.

Respiratory: Diffuse rales but no wheezing or stridor.

CVS: Tachycardic, regular rhythm, soft systolic murmur.

Abdomen: Soft, non-tender, no tenderness, no guarding, no hepato-

splenomegaly

Lymph: No cervical lymphadenopathy

Extremities: No peripheral edema, normal tone, normal range of movement

\section{Laboratory}

CBC: WBC $20.2 \times 10^{3} / \mu \mathrm{L}$, hemoglobin $9.3 \mathrm{~g} / \mathrm{dL}$, hematocrit $29.8 \%$, platelets $272,000 / \mu \mathrm{L}$.

Chemistries: $\mathrm{Na}^{+} 134 \mathrm{meq} / \mathrm{L}, \mathrm{K}^{+} 4.8 \mathrm{meq} / \mathrm{L}, \mathrm{Cl}^{-} 108 \mathrm{meq} / \mathrm{L}, \mathrm{CO}_{2} 19 \mathrm{mmol} / \mathrm{L}$, blood urea nitrogen (BUN) $58 \mathrm{mg} / \mathrm{dL}$, creatinine $1.7 \mathrm{mg} / \mathrm{dL}$, glucose $272 \mathrm{mg} / \mathrm{dL}$, calcium $9.7 \mathrm{mg} / \mathrm{dL}$, albumin $2.2 \mathrm{~g} / \mathrm{dL}$, liver function test-within normal limits.

Prothrombin time (PT) $28.0 \mathrm{sec}$, international normalized ratio (INR) 2.5, partial thromboplastin time (PTT) $44.5 \mathrm{sec}$

An old chest x-ray and CT scan were reviewed (Figure 1).

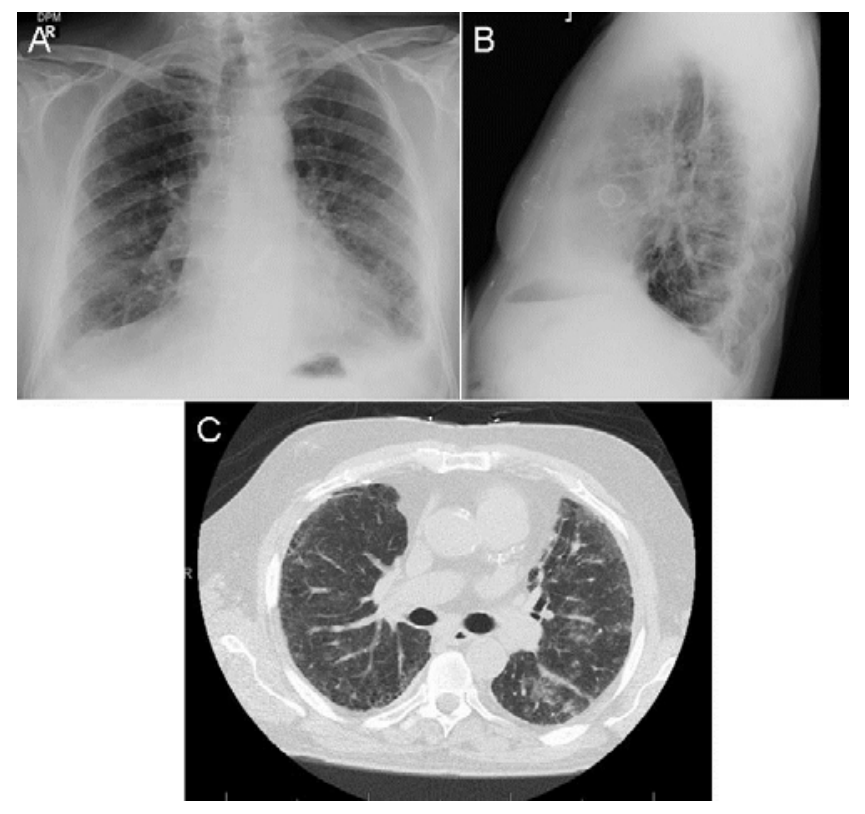

Figure 1. Old PA (panel $A$ ) and lateral (Panel B) and representative image from an old CT scan (panel C). 
Which of the followings are the findings of asbestos related disease on chest $x$-ray? (click on correct answer to move to next panel)

1. Reticular or patchy opacity

2. Calcified pleural plaque

3. Bilateral consolidation

4. Pulmonary edema

5. $1+2$

6. $3+4$ 


\section{Correct!}

\section{$5.1+2$}

Asbestos fiber inhalation can lead to diverse pulmonary disorders including asbestosis, pleural disease and malignancy. Asbestosis represents diffuse pulmonary fibrosis, and peripheral reticular opacities with lower lung field predilection are the characteristic chest $x$-ray findings. CT scan helps diagnosis of early stage asbestosis with normal chest x-ray finding, and subpleural curvilinear lines, pleural thickening, lobular septal thickening, and honeycombing change are commonly found on CT image (1).

Later on the same day, patient developed severe hypoxemia requiring intubation and ICU transfer. The arterial blood gases (ABG) before intubation were as follows:

ABG: pH 7.37, $\mathrm{pCO}_{2} 36.0 \mathrm{mmHg}, \mathrm{pO}_{2} 68.0 \mathrm{mmHg} \mathrm{HCO}_{3}{ }^{-} 20.8 \mathrm{meq} / \mathrm{L}, \mathrm{SaO}_{2}$ $90.8 \%$ while receiving $10 \mathrm{~L} \mathrm{O}_{2} \mathrm{NRB}$

Broad spectrum coverage for bacterial and fungal disease was begun with vancomycin, azithromycin, meropenem and fluconazole. However, testing for mycoplasma, coccidioidomycosis, legionella, respiratory viral panel, sputum, and blood cultures were all negative. Subsequent bronchoalveolar lavage showed a cell count of $0.46 \times 10^{6}$ and a differential of $83 \%$ neutrophils, $3 \%$ lymphocytes, $13 \%$ macrophages, and $1 \%$ eosinophils with no evidence of infection.

A chest $x$-ray and chest CT were performed after intubation (Figure 2).
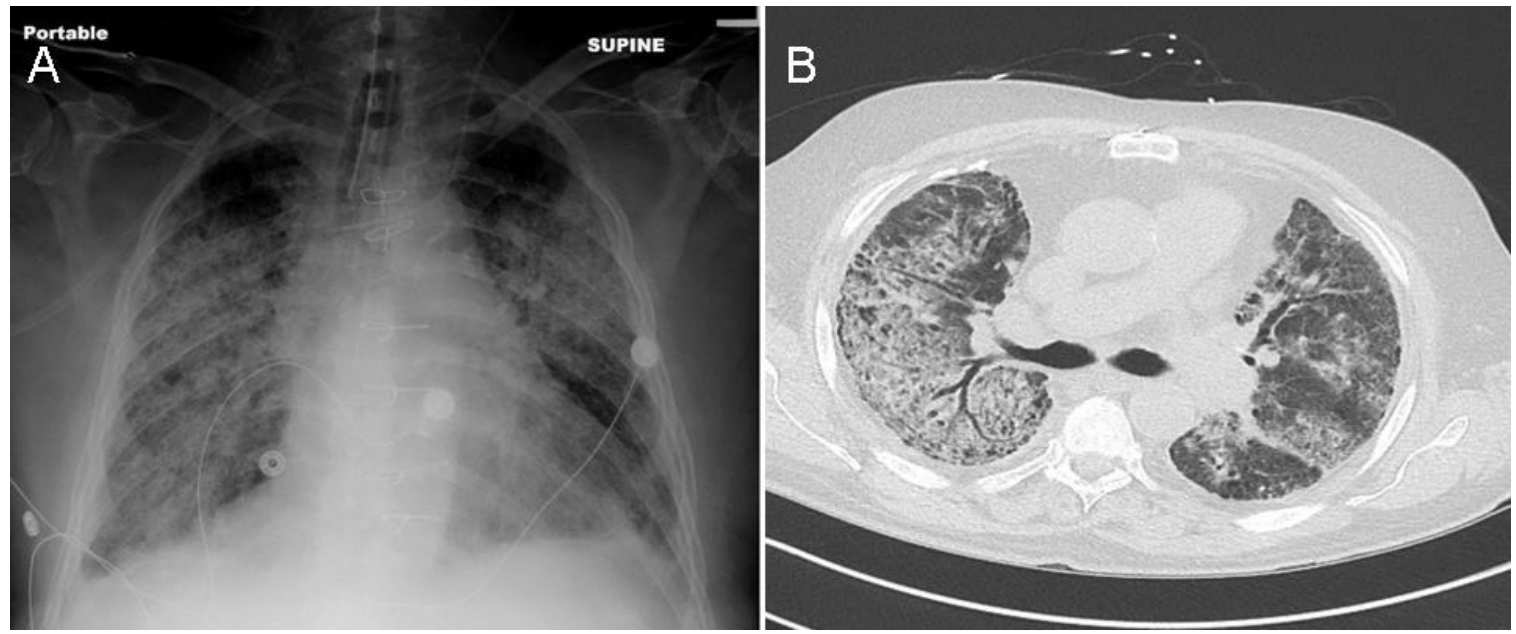

Figure 2. Portable AP of chest (Panel A) and representative lung window from thoracic CT scan (Panel B) performed after intubation. 
What is the most common cause of respiratory decompensation in interstitial lung disease (ILD) patients? (click on correct answer to move to next panel)

1. Complication of immune suppressing treatment

2. Congestive heart failure

3. Idiopathic

4. Infection

5. Pulmonary hypertension

6. Venous thromboembolism 


\section{Correct!}

\section{Idiopathic}

Acute exacerbation is one of the main prognostic factors predicting increased mortality of ILD patients. For instance, the mortality rate of acute exacerbation in IPF patients is $60 \sim 100 \%$, and it is the main cause of death. The definition of an acute exacerbation in ILD patients includes the following criteria (2).

- Concurrent diagnosis of interstitial lung disease;

- Aggravating symptoms;

- Hypoxemia worse that pre-exacerbation (decreased PaO2/FiO2);

- New ground glass opacities or consolidations on images;

- Exclusion of other causes that can cause aggravation of symptoms such as infection, pulmonary hypertension, congestive heart failure and pulmonary embolism.

Multiple factors including infection, pulmonary embolism, heart failure, chemo- or radio-therapy for lung cancer, BAL, and complication of immune suppressing agents, can exacerbate underlying ILD, however a clear etiology cannot be found in the majority of ILD patients with acute exacerbation. Several hypothesis such as genetic factors, occult aspiration and viral infection have been suggested although no clear evidence to support any of these (2).

The patient is now on mechanical ventilator in the volume control mode with a positive end expiratory pressure (PEEP) of $14 \mathrm{~cm} \mathrm{H} 2$ ), respiratory rate 14 breaths/min, tidal volume (TV) $380 \mathrm{ml}$, and the fraction of inspired oxygen (FiO2) of $60 \%$. ABGs were as follows:

ABG: $\mathrm{pH} 7.34, \mathrm{pCO}_{2} 45.4 \mathrm{mmHg}, \mathrm{pO}_{2} 168.3 \mathrm{mmHg} \mathrm{HCO}_{3}{ }^{-} 24.8 \mathrm{meq} / \mathrm{L}, \mathrm{SaO}_{2}$ $96.3 \%$

What is the most appropriate ventilator mode in diffuse interstitial lung disease? (click on correct answer to move to next panel)

1. High PEEP, high tidal volume

2. High PEEP, low tidal volume

3. Low PEEP, high tidal volume

4. Low PEEP, low tidal volume

5. None of the above 


\section{Correct! \\ 2. High PEEP, low tidal volume}

Repetitive opening and closing of alveoli upon mechanical ventilation can cause injury in lung parenchyma, which is called ventilator induced lung injury (VILI). It can lead to multi-organ failure through dissemination of proinflammatory cytokines and enzymes, therefore, a protective ventilation strategy is pivotal in patients with ARDS or ALI. The ARDS Clinical Network recommends a low tidal volume ( $\leq 8 \mathrm{ml} / \mathrm{kg} \mathrm{PBW}$ ) with a goal plateau pressure $\leq 30 \mathrm{~cm} \mathrm{H}_{2} \mathrm{O}$ (3). A recent meta-analysis showed high PEEP might increase survival in ARDS patient, but may be harmful in ALI patients without ARDS (4). However, most of these studies excluded patients with known interstitial lung disease such as idiopathic pulmonary fibrosis and cryptogenic organizing pneumonia, and it is unclear whether these mechanical ventilator strategies for ARDS or ALI work the same way in ILD patients. One recent retrospective study with ILD patients showed a high PEEP > $10 \mathrm{~cm} \mathrm{H}_{2} \mathrm{O}$ was associated with a significant survival benefit (5). Although there is no definitive evidence, a low tidal volume with high PEEP is the current recommendation for ILD patients who need mechanical ventilation to minimize volutrauma, atelectotrauma and maximized oxygenation.

There was little improvement in our patient with antibiotic treatment, and ventilator weaning was difficult. The diffuse chest $x$-ray and CT findings along with the nonspecific BAL cytology suggested the diagnosis of cryptogenic organizing pneumonia.

What is the best initial treatment for an acute exacerbation of cryptogenic organizing pneumonia? (click on correct answer to move to next panel)

1. Antibiotics

2. Anticoagulation

3. Cyclophosphamide

4. Glucocorticoids

5. Pirfenidone 


\section{Correct! \\ 4. Glucocorticoids}

Cryptogenic organizing pneumonia (COP) is one of the many causes of diffuse interstitial lung disease. Histologic findings of COP include extensive proliferation of granulation tissues affecting distal bronchioles and alveolar walls with patchy and peribronchiolar distribution (5). Patients with COP most commonly present with flu-like symptoms including cough, dyspnea, fever and general weakness, which are resistant to antibiotic treatment. There is no specific laboratory test for COP, and only $50 \%$ of patients have leukocytosis. Glucocorticoids with careful attention to their adverse effect are recommended as an initial treatment for COP patients with persistent or worsening symptoms $(6,7)$. Cytotoxic agents such as cyclophosphamide can be an alternative option for the patients who are refractory to steroid treatment.

High dose glucocorticoids were started. The patient's respiratory status improved rapidly, and he was extubated successfully.

Which of the following disease is not included in steroid responsive interstitial lung disease? (click on correct answer to move to next panel)

1. Acute interstitial pneumonia (AIP)

2. Desquamative interstitial pneumonia (DIP)

3. Idiopathic pulmonary fibrosis (IPF)

4. Nonspecific interstitial pneumonia (NSIP)

5. Respiratory bronchiolitis interstitial lung disease (RBILD) 


\section{Correct! \\ 3. Idiopathic pulmonary fibrosis (IPF)}

Most of the interstitial lung diseases respond well to steroid treatment except IPF. No treatment has been shown to be effective in IPF. Azathioprine, Nacetylcysteine and a steroid combination is often used, however, combination therapy cannot change the course of IPF. Additionally, a recent clinical trial showed combination therapy is associated with a higher mortality and more adverse effects than placebo (8).

\section{References}

1. American Thoracic Society. Diagnosis and initial management of nonmalignant diseases related to asbestos. Am J Respir Crit Care Med. 2004;170(6):691-715. [CrossRef] [PubMed]

2. Papanikolaou IC, Drakopanagiotakis F, Polychronopoulos VS. Acute exacerbations of interstitial lung diseases. Curr Opin Pulm Med. 2010;16(5):480-6. [CrossRef] [PubMed]

3. The Acute Respiratory Distress Syndrome Network. Ventilation with lower tidal volumes as compared with traditional tidal volumes for acute lung injury and the acute respiratory distress syndrome. $\mathrm{N}$ Engl J Med. 2000;342(18):1301-8. [CrossRef] [PubMed]

4. Briel M, Meade M, Mercat A et al. Higher vs lower positive end-expiratory pressure in patients with acute lung injury and acute respiratory distress syndrome: systematic review and meta-analysis. JAMA. 2010;303(9):865-73. [CrossRef] [PubMed]

5. Fernández-Pérez ER, Yilmaz M, Jenad H, Daniels CE, Ryu JH, Hubmayr RD, Gajic $\mathrm{O}$. Ventilator settings and outcome of respiratory failure in chronic interstitial lung disease. Chest. 2008;133(5):1113-9. [CrossRef] [PubMed]

6. Cordier JF. Cryptogenic organising pneumonia. Eur Respir J. 2006;28(2):42246. [CrossRef] [PubMed]

7. Lazor R, Vandevenne A, Pelletier A, Leclerc P, Court-Fortune I, Cordier JF. Cryptogenic organizing pneumonia. Characteristics of relapses in a series of 48 patients. The Groupe d'Etudes et de Recherche sur les Maladles "Orphelines" Pulmonaires (GERM"O"P). Am J Respir Crit Care Med. 2000;162(2 Pt 1):571-7. [PubMed]

8. National Institutes of Health. Commonly used three-drug regimen for idiopathic pulmonary fibrosis found harmful. Available at: http://www.nih.gov/news/health/oct2011/nhlbi-21.htm (accessed 2/11/14). 